\section{P23 EFFECT OF OMALIZUMAB ON ORAL CORTICOSTEROID REQUIREMENTS OF YOUNG CHILDREN WITH SEVERE ASTHMA; RESULTS OF A UK SURVEY}

doi:10.1136/thx.2010.150961.23

${ }^{1} \mathrm{~A}$ Kirk, ${ }^{1} \mathrm{D}$ Spencer, ${ }^{2} \mathrm{~A}$ Radwan. ${ }^{1}$ Great North Children's Hospital, Newcastle-uponTyne, UK; ${ }^{2}$ Novartis Pharmaceuticals UK Limited, Frimley/Camberley, Surrey, UK

Introduction and Objectives Some children with severe chronic asthma require long-term oral corticosteroids (OCS) to maintain disease control which places them at risk of potentially serious adverse effects. Omalizumab is a recombinant, humanised, monoclonal anti-IgE antibody indicated in the EU for use in patients of $\geq 6$ years of age with inadequately controlled severe allergic asthma. This agent improves disease control in children, adolescents and adults. We conducted an observational survey in UK clinical centres to evaluate whether omalizumab enabled reduction of OCS dose in children with severe, persistent, allergic asthma.

Methods Seven UK clinical centres were identified in which children ( 6 to $<12$ years of age) with severe persistent allergic asthma were being treated with omalizumab. Lead clinicians at each centre were approached to request their participation and, if they agreed, they were sent a short questionnaire. Participating clinicians provided information on children who had continued treatment with omalizumab beyond the 16 -week responder assessment. Information collected included the number of children receiving omalizumab, OCS use, OCS dose at omalizumab initiation, numbers of children stopping, reducing or increasing OCS use, and current OCS doses.

Results Information was provided from four sites for 18 children receiving omalizumab, all of whom were on maintenance OCS at baseline. All patients were able to stop or reduce their OCS dose after initiating omalizumab. Four patients (22\%) on a mean baseline OCS dose of $8.8 \mathrm{mg} /$ day stopped using OCS altogether. In the remaining fourteen patients $(78 \%)$ the OCS dose was reduced by a mean of $15.4 \mathrm{mg}$ (from $22.0 \mathrm{mg}$ to $6.5 \mathrm{mg}$; mean $70.2 \%$ reduction). The mean dose reduction across all patients of $77 \%$ was achieved in a mean time of 14.6 weeks.

Conclusions In this observational survey, all paediatric patients with severe allergic asthma who were commenced on omalizumab were able to stop or reduce OCS use, potentially reducing the risk of OCS-related adverse effects. The reductions in OCS use occurred over a short period, raising the possibility that further reductions in OCS dose might be feasible in some patients over a longer period of time.

\section{P24 FLUTICASONE PROPIONATE/FORMOTEROL FUMARATE COMBINATION THERAPY HAS A MORE RAPID ONSET OF ACTION THAN FLUTICASONE PROPIONATE/SALMETEROL XINAFOATE IN THE TREATMENT OF ASTHMA: A RANDOMISED CONTROLLED TRIAL}

doi:10.1136/thx.2010.150961.24

${ }^{1} \mathrm{~A}$ Bodzenta-Lukaszyk, ${ }^{2} \mathrm{~A}$ Dymek, ${ }^{3} \mathrm{H}$ Mansikka. ${ }^{1}$ Clinical Department of Allergology and Internal Diseases, Uniwersytet Medyczny w Białymstoku, Białystok, Poland; ${ }^{2}$ Centrum Medyczne Lucyna Andrzej Dymek, Strzelce Opolskie, Poland; ${ }^{3}$ Mundipharma Research Limited, Cambridge, UK

Introduction and objectives A new asthma therapy combining fluticasone propionate and formoterol fumarate (FP/FORM) in a single pressurised metered dose inhaler has been shown to have similar efficacy and safety to fluticasone propionate/salmeterol xinafoate (FP/SAL). Secondary endpoint data for this study are presented here. Methods Adults $(\mathrm{N}=202)$ with mild to moderate-severe asthma were randomised 1:1 to 12 weeks of treatment with FP/FORM (100/
$10 \mu \mathrm{g}$ or $250 / 10 \mu \mathrm{g})$ or FP/SAL $(100 / 50 \mu \mathrm{g}$ or $250 / 50 \mu \mathrm{g})$, both twice daily, in an open-label, parallel-group, multicentre study. The starting dose was based on the dose of inhaled corticosteroid the patient received before the study. The primary endpoint was mean morning pre-dose $\mathrm{FEV}_{1}$ at Week 12. Secondary endpoints included time to onset of action. Time to onset of action was defined as the first time point post-dose at which the $\mathrm{FEV}_{1}$ value was at least $12 \%$ greater than the pre-dose value (Abstract P24 Figure 1).

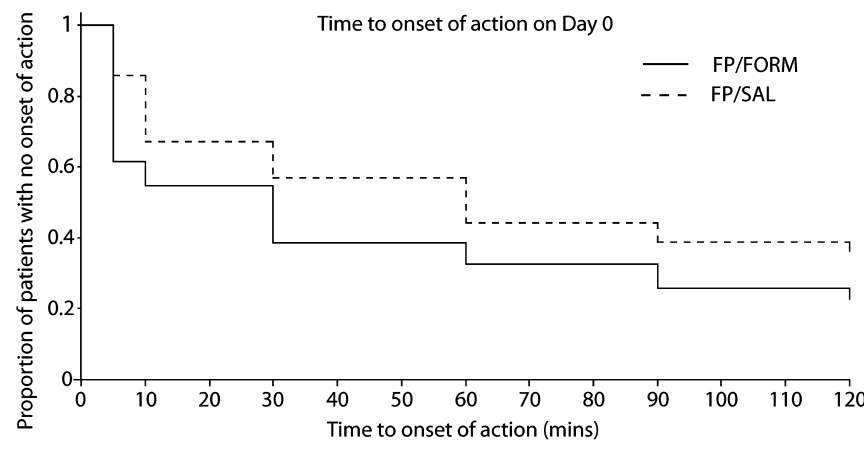

FP/FORM = fluticasone propionate/formoterol fumarate; FP/SAL = fluticasone propionate/salmeterol xinafoate

\section{Abstract P24 Figure 1}

Results FP/FORM time to onset of action was more rapid than FP/ SAL (HR: 1.64 ; 95\% CI: 1.28 to 2.10 ; $p<0.001$; full analysis population; FP/FORM: $\mathrm{n}=101$; FP/SAL: $\mathrm{n}=100)$. Onset of action was observed on Day 0 in 78 patients in the FP/FORM group and 64 patients in the FP/SAL group. The probability of onset of action occurring was higher in the FP/FORM group than in the FP/SAL group at each post-dose time point on Days $0,14,42$ and 84 . In total, $72.3 \%(73 / 101)$ patients started on FP/FORM 250/10 $\mu \mathrm{g}$ and 75.2\% (76/101) on FP/SAL 250/50 $\mu$ g. Eight patients (FP/FORM: $\mathrm{n}$ $=5 ; \mathrm{FP} / \mathrm{SAL}: \mathrm{n}=3$ ) required an increase in dose. Overall, the rate of AEs was comparable (23.8\%; 24/101 for both groups). Most AEs were mild or moderate. There were only two severe AEs, both in the FP/FORM group. The frequency of treatment-related AEs was very low in both groups (FP/FORM: $\mathrm{n}=1$; FP/SAL: $\mathrm{n}=1$ ). Clinical laboratory results and vital sign assessments showed no abnormal results. No clinically important ECG changes were observed. Overall, FP/FORM and FP/SAL safety and tolerability profiles were similar.

Conclusion FP/FORM improved lung function more rapidly than FP/SAL

\section{P25 RELATIONSHIPS BETWEEN AIRWAY HYPER- RESPONSIVENESS, AIRWAY INFLAMMATION AND AIRWAY CALIBRE IN ASTHMATIC SUBJECTS}

doi:10.1136/thx.2010.150961.25

${ }^{1} \mathrm{PM}$ Short, ${ }^{2} \mathrm{SIW}$ Lipworth, ${ }^{1} \mathrm{BJ}$ Lipworth. ${ }^{1}$ Asthma and Allergy Research Group, University of Dundee, Dundee, UK; ${ }^{2}$ Bute Medical School, University of St. Andrews, St. Andrews, UK

Introduction and Objectives We wished to examine therelationships between inflammation ( $\mathrm{FE}_{\mathrm{NO}}$ ), methacholine challenge (AHR) and airway calibre (FEV1\%) in a group of mild-to-moderate asthmatics. Methods We searched our patient database forthose individuals with a known diagnosis of asthma who had a methacholine $\mathrm{PC}_{20} \leq 8 \mathrm{mg} /$ $\mathrm{ml}$. Data regarding $\mathrm{FEV} 1 \%$, $\mathrm{FE}_{\mathrm{NO}}$, skinprick and methacholine $\mathrm{PC}_{20}$ were collected and divided into groups based upon AHR: severe $(<0.5 \mathrm{mg} / \mathrm{ml})$, moderate $(>0.5-2 \mathrm{mg} / \mathrm{ml})$ and mild $(>2-8 \mathrm{mg} / \mathrm{ml})$ and $\mathrm{FE}_{\mathrm{NO}}$ : low (<25 ppb), medium $(25-50 \mathrm{ppb})$ and high ( $\left.>50 \mathrm{ppb}\right)$. Results We identified 208 who had a known diagnosis of asthma, a methacholine $\mathrm{PC}_{20} \leq 8 \mathrm{mg} / \mathrm{ml}$, as well as $\mathrm{FE}_{\mathrm{NO}}$ and skin prick testing. 